Biological and Clinical Sciences Research Journal

ISSN: 2708-2261

www.bcsrj.com

DOI: https://doi.org/10.54112/bcsrj.v2020i1.13

Biol. Clin. Sci. Res. J., Volume, 2020: 13

MEDEYE

Original Research

\title{
ASSESSMENT OF NURSES MANAGEMENT SKILLS FOR CRITICALLY ILL PATIENTS
}

\author{
*ALI S ${ }^{1}$, GILLANI SA ${ }^{2}$, AFZAL $M^{1}$, PERVEEN K ${ }^{1}$ \\ ${ }^{1}$ Lahore School of Nursing, The University of Lahore, Lahore, Pakistan \\ ${ }^{2}$ Allied Health Sciences, The University of Lahore, Lahore, Pakistan \\ *Corresponding author email: pbsn02183050@student.uol.edu.pk
}

(Received, $5^{\text {th }}$ May 2020, Revised $25^{\text {th }}$ June 2020, Published $2^{\text {nd }}$ July 2020)

\begin{abstract}
The Nurses usually use physical restraints for maintaining patients' therapies and devices in a critical ill setting like ICU, like central lines, endotracheal tubes and the arterial lines. It has been found that about up to $78 \%$ among the critical ill patients who have been admitted into various types of ICUs and may have a need for applying a physical self-possession due to the alterations found among their levels of the awareness while during their stay at ICU ward. The nurses' attitude, knowledge and their practice for physical self-control played a vital role for nursing care which has to be provided for restrained patients to prevent form complications in ICU. We have conducted our research to assess nurse's attitudes, knowledge and practice regarding their physical self-control among the most critically ill patients in ICU. We have used a descriptive type of design for our study. The number of nurses used for our study was 66 in total who are working at Lahore School of Nursing, The University of Lahore, Lahore, Pakistan. From our study most of the samples were female, who had a bachelor degree in nursing, with experience of more than 5 years, the aged was ranged between 21-30 years old, along with not attended any of the previous degree or equivalent educational program related with self-control or restraints were under consideration. It was found from our study that majority of samples under study were with reasonable level of nursing knowledge, offensive type of attitude however, around $90.8 \%$ out of all nurses showed a satisfactory and moderate type of practice for applications of the physical self-control or restraints for critical ill patients in ICU. It was frond from correlation among the socio-demograhpic characters and nurses' knowledge, the practice and attitude, no significant type of correlation was recorded while among the nurses' age vs knowledge, the practice and attitude, a significant and positive correlation was found while among the nurses' knowledge, gander and practice was also found a significant correlation along with nurse's practice and qualification, a significant positive correlation was also among the nurses' practice score, attitude and experience. It was concluded from our study that, a reasonable level of nurses' improper attitude, knowledge and a satisfactory practice for physical self-control or restraints was found among the critically ill patients in ICU. From our study we have suggested that there must be some proper training programs to teach nurses to develop their knowledge and physical restraints while working in ICU for proper care of patients.
\end{abstract}

Keywords: ICU, critical ill patients, nurses' knowledge, physical restraints, attitude, practice, consciousness alteration

Introduction

Special care with constant nursing monitoring is necessary for critically ill patients to help them recover from life threatening conditions or injuries (Kandeel and Attia, 2013) additionally, these patients are prone to develop altered consciousness level i.e confusion, thus can try to get rid of connected life support and monitoring devices including nasogastric tube, endotracheal tubes, arterial line, and central lines which can harm themselves (Azab and Abu Negm, 2013). About $80 \%$ of severely ill patients that admitted to a variety of ICUs require application of physical restraints because of change in their consciousness level during ICU stay (Phillips, 2013). Use of physical restraint within surgical ICU patients was much lower (14.5 to $34 \%$ ) than medical ICU patients (12.6 to 50.1\%) (Martin and Mathisen, 2005). Physical restraint refers to "any device ,substance or equipment that is used to restrict any physical activity or free movement of patient including usual access to his/her own body (Elsatar and El-latief, 2015). The prevalence of physical restraints application is $62 \%$ and $65 \%$ in confused patient in order to avoid falling risk. Though this is a difficult decision and depends on patient characters, the practitioner, and the environment. There are a variety of restraints including mitts and wrist restraints, elbow immobilizers, vests, belts, leg restraints as well as bed side barriers (Ang et al., 2015; Taha and Ali, 2013). Maintaining patient safety

[Citation: Ali, S., Gillani, S.A., Afzal, M., Perveen, K. (2020). Assessment of nurses management skills for critically ill patients. Biol. Clin. Sci. Res. J., 2020: 13 doi: https://doi.org/10.54112/bcsrj.v2020i1.13] 
is the main indication in use of physical or chemical restraint during the change in her or his level of consciousness. The limitation of chemical restraint is increased risk of sedation. Thus, Application of physical restraint in confused patients limits interference while providing nursing care (Younis and Sayed Ahmed, 2017). Use of physical restraint is contraindicated in patient with edema, aspiration, breathing problems, contractures, fractures, paralysis and pressure ulcers .An informed consent must be taken from patient or his/her family as ethical consideration (Elsatar and El-latief, 2015). As it effects patient and family reactions such as low patient's self-esteem, increased anxiety, fear, loneliness and detention. It also has effect on nurse's feelings including guilt, disappointment, and embarrassment when they apply physical restraint to their patients (De Jonghe et al., 2013). Critically ill patients develop some complications due to physical restraint application such as limb edema, restricted circulation, pressure sore, and also skin laceration at restraint site (Strout, 2010). Close monitoring and alteration in nursing care plan can preclude theses complications. Given that, nursing care plan should consists of regular and frequent change of patient's position with sufficient range of movement (Elsatar and El-latief, 2015), removal of restraints for every two hours, assessment of the patient's response hourly and also skin care (Kandeel and Attia, 2013). Application of physical restraints can be affected by numerous factors such as number of nurses, their attitude, experience, qualification and knowledge about the use of physical restraint. These factors accounts for their major role in providing nursing care to restrained patients and prevent its complications. The KAP study outlines the correlation of restraint effect with nursing care and identification of the strengths and weakness (Nasrate et al., 2017). Thus, the study was aimed to assess nurse's knowledge, attitude and practice, concerning physical restraints in critically ill patients.

\section{Significance of the study}

The food and drug administration (FDA) reported the death rate of at least 100 individuals per year in USA due to lack of practice in application of physical restraints (Elsatar and El-latief, 2015). Rate of application of physical restraints is higher in ICU patients than other ward patients; $33 \%-68 \%$ and $30 \%$ respectively (Goethals et al., 2013). Physical restraint is among the most conventional practice in ICU patients. Though there is insufficient data regarding the evaluation of nurses' knowledge, attitude and practice for physical restraint application in critically ill patients. This assessment is very significant because it identifies the need of nursing education and training, which is necessary in training competent nurses with good practice for physical restraint patients.

\section{The aim of the study}

To assess nurse's knowledge, attitudes, and practice about physical restraints in critically ill patients.

\section{Research question}

Q1: What are the nurses' knowledge, attitudes, and practice regarding physical restraints?

Q2-Is there a relationship between nurse's knowledge, attitudes, and practice and their sociodemographic features?

\section{Materials and methods}

A descriptive type of hospital based study design was used for this study. The present study was carried out in the ICU, Intermediate A, and B, at The Lahore University Teaching Hospital, The University of Lahore, Lahore. The targeted population of our study was consisted of 66 nurses who are working at The Lahore University Teaching Hospital during our current study period. Our study inclusion criteria were nurses willing for participation and the nurses who were on vocation. The data were collected through using the structured questionnaire interviews. The demographic data which was related to the nurses for our study was included following of the characteristics: nurses' sex, age, qualification, a number of years' experience, previous education on physical restraint, and type of ICU. The tools were tested for their content by three experts in the field of Medical-Surgical Nursing and Pediatric Nursing to ascertain relevance and completeness.

\section{Results}

The results from table 1 showed that the higher number of nurses was from age ranged 21-30 years old with $56.061 \%$ from total 66 nurses who were kept under study. The females were 49 with $74.242 \%$ along with bachelor education with same number and percentage. The experience was found higher for more than 5 years $59.091 \%$. The higher number of nurses was from ICU (39.394\%).

Table 1. Socio-demographic characteristics of nurses

\begin{tabular}{llll}
\hline Socio-demographic characteristics & & \multicolumn{2}{c}{ Study group $(\mathbf{n = 6 6})$} \\
& & No. & \% \\
\hline \multirow{3}{*}{ Age (years) } & $21-30$ years old & 37 & 56.061 \\
& $31-40$ years old & 19 & 28.788 \\
Gender & $41-50$ years old & 10 & 15.152 \\
& Male & 17 & 25.758 \\
& Female & 49 & 74.242 \\
\hline
\end{tabular}

[Citation: Ali, S., Gillani, S.A., Afzal, M., Perveen, K. (2020). Assessment of nurses management skills for critically ill patients. Biol. Clin. Sci. Res. J., 2020: 13 doi: https://doi.org/10.54112/bcsrj.v2020i1.13] 


\begin{tabular}{llll}
\hline \multirow{2}{*}{ Qualification } & Diploma & 4 & 6.061 \\
& Bachelor & 49 & 74.242 \\
& Master & 13 & 19.697 \\
Experience years & Less than 5 years & 27 & 40.909 \\
& More than 5 years & 39 & 59.091 \\
Previous education & Yes & 23 & 34.848 \\
program on physical & No & 43 & 65.152 \\
restraint & & & \\
& & & \\
Type of CC Nurses & Intermediate A(CCU 1) & 17 & 25.758 \\
& Intermediate B(CCU 2) & 23 & 34.848 \\
\hline
\end{tabular}

Table 2: Assessment of nurses` knowledge regarding physical restraints among critical ill patients (n=66)

\begin{tabular}{|c|c|c|c|}
\hline Question statements & $\begin{array}{l}\text { Agree } \\
\text { No }(\%)\end{array}$ & $\begin{array}{l}\text { Disagree } \\
\text { No }(\%)\end{array}$ & Mean \pm SD \\
\hline $\begin{array}{l}\text { Physical restraints designed to prevent patient's injury and their application } \\
\text { was safety. }\end{array}$ & $54(81.818$ & $12(18.182)$ & $0.516 \pm 0.237$ \\
\hline A restraint is legal only if it is necessary from patient harm. & $41(62.121$ & ) $25(37.879)$ & $0.358 \pm 0.249$ \\
\hline aint. & $28(42.424$ & $38(57.576)$ & $0.403 \pm 0.150$ \\
\hline s applic & $31(46.970$ & $35(53.030)$ & $0.428 \pm 0.251$ \\
\hline $\begin{array}{l}\text { The disturbance in the patient's level of consciousness disturbance requires application } \\
\text { of a restraint. }\end{array}$ & $24(36.364$ & $42(63.636)$ & $0.312 \pm 0.147$ \\
\hline The nurse should be released a restraint every 2 hours. & $37(56.061$ & ) $29(43.939)$ & $0.058 \pm 0.149$ \\
\hline $\begin{array}{l}\text { Restraints should be applied not tightly, with pad between the restraint and } \\
\text { patient's skin. }\end{array}$ & $12(18.182$ & $54(81.818)$ & $0.112 \pm 0.232$ \\
\hline 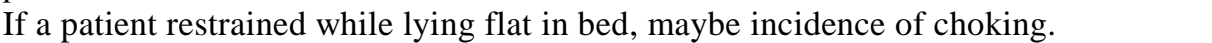 & 41( & & $0.067 \pm 0.147$ \\
\hline $\begin{array}{l}\text { There is many patients' complication due to physical restraints as skin breaks up or } \\
\text { restlessness. }\end{array}$ & $58(87.879$ & $8(12.121)$ & $0.288 \pm 0.232$ \\
\hline 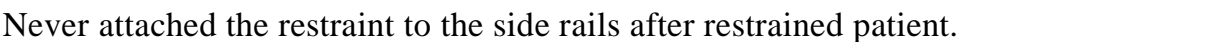 & $27(40.909$ & ) $39(59.091)$ & $0.243 \pm 0.250$ \\
\hline Assessment and record for the restrained patient are important every shift. & $51(77.273$ & $15(22.727)$ & $0.808 \pm 0.132$ \\
\hline A nurse can be charged with assault if he/she applies restraints when they are & $37(56.061)$ & $29(43.939)$ & $0.502 \pm 0.050$ \\
\hline $\begin{array}{l}\text { In an emergency situation, it is legally a nurse can restrain a patient without a } \\
\text { physician's order. }\end{array}$ & $11(16.667)$ & ) $55(83.333)$ & $0.123 \pm 0.334$ \\
\hline & & & \\
\hline May be the presence of a relationship between the deaths and the use of vest & $37(56.061)$ & $29(43.939)$ & $0.423 \pm 0.250$ \\
\hline
\end{tabular}
restraints.

Total nurses`knowledge mean score regarding Physical Restraints among Critical Ill Patients

$8.355 \pm 2.926$

The results from table 2 indicated that the nurses` nurses` attitude mean score regarding physical knowledge mean score regarding physical restraints restraints among critical ill patients was found as among Critical Ill Patients was found as 19.37 \pm 2.23 .

8.355 \pm 2.926 . The results from table 3 indicated that

Table 3: Assessment of nurses`attitude regarding physical restraints among critical ill patients $(n=66)$

\begin{tabular}{|c|c|c|c|c|}
\hline Statement & $\begin{array}{l}\text { Agree } \\
\text { No }(\%)\end{array}$ & $\begin{array}{l}\text { Disagree } \\
\text { No }(\%)\end{array}$ & $\begin{array}{l}\text { Non } \\
\text { decided } \\
\text { No }(\%) \\
\end{array}$ & $\begin{array}{l}\text { Mean } \pm \\
\text { SD }\end{array}$ \\
\hline I think that patient's family members have the right to refuse the use of restraints. & $23(34.85$ & ) $10(15.15$ & $33(50.00)$ & $0.57 \pm 0.54$ \\
\hline I think that the nurses have the right to refuse the application of patient restraints. & $12(18.18$ & ) $14(21.21$ & ) $34(51.52)$ & $0.43 \pm 0.69$ \\
\hline $\begin{array}{l}\text { If, } i \text { am a patient, I should have the right to refuse/oppose when restraints apply to } \\
\text { me. }\end{array}$ & $45(68.18$ & $17(25.76$ & $4(6.06)$ & $1.54 \pm 0.64$ \\
\hline I believe that placing a patient in restraints is wrong. & 11(16.67 & ) $23(34.85$ & ) $32(48.48)$ & $0.23 \pm 0.44$ \\
\hline $\begin{array}{l}\text { I think that the main cause of restraints application in the hospital is limited staff } \\
\text { number. }\end{array}$ & $36(54.55$ & ) $17(25.76$ & ) $13(19.70)$ & $1.14 \pm 0.57$ \\
\hline I feel with uncomfortable senses when the family enters the patient's room, and they & $39(59.09$ & ) $19(28.79$ & ) $8(12.12)$ & $1.26 \pm 0.81$ \\
\hline
\end{tabular}

[Citation: Ali, S., Gillani, S.A., Afzal, M., Perveen, K. (2020). Assessment of nurses management skills for critically ill patients. Biol. Clin. Sci. Res. J., 2020: 13 doi: https://doi.org/10.54112/bcsrj.v2020i1.13] 
see

him/ her restrained.

The hospital administration is legally responsible for using restraints to keep the patient $35(53.03) 26(39.39) 5(7.58)$

$1.34 \pm 0.22$

safe.

It makes me feel terrible if the patient gets more upset after restraints are applied.

$25(37.88) 28(42.42) 13(19.70)$

$1.27 \pm 0.54$

I think that it is more important to let the patients with agitation or disturbed $23(34.85) 33(50.00) 10(15.15)$

$0.76 \pm 1.2$

consciousness

levels in restraints during I provide care for them.

I think that a patient suffers a loss of dignity when placed in restraints.

$17(25.76) 28(42.42) 21(31.82)$

$1.17 \pm 0.34$

In general, I think that I have all knowledge needed for caring for a restrained patient. $\quad$ 19(28.79) 26(39.39) 21(31.82)

$1.29 \pm 0.23$

Total nurses`attitude mean score regarding Physical Restraints among critical ill patients

$19.37 \pm 2.23$

The results from table 4 showed relationship among socio-demograhpic characters and nurses knowledge, attitude and practice regarding their physical restraints among the critical ill patients. The results showed that there was no significant correlation among the nurses' age with knowledge, the attitude with practice regarding the physical restraints faced by them. It was found that here was

Table 4: Relationship among socio-demograhpic characters and nurses` knowledge, attitude and practice regarding physical restraints among critical ill patients

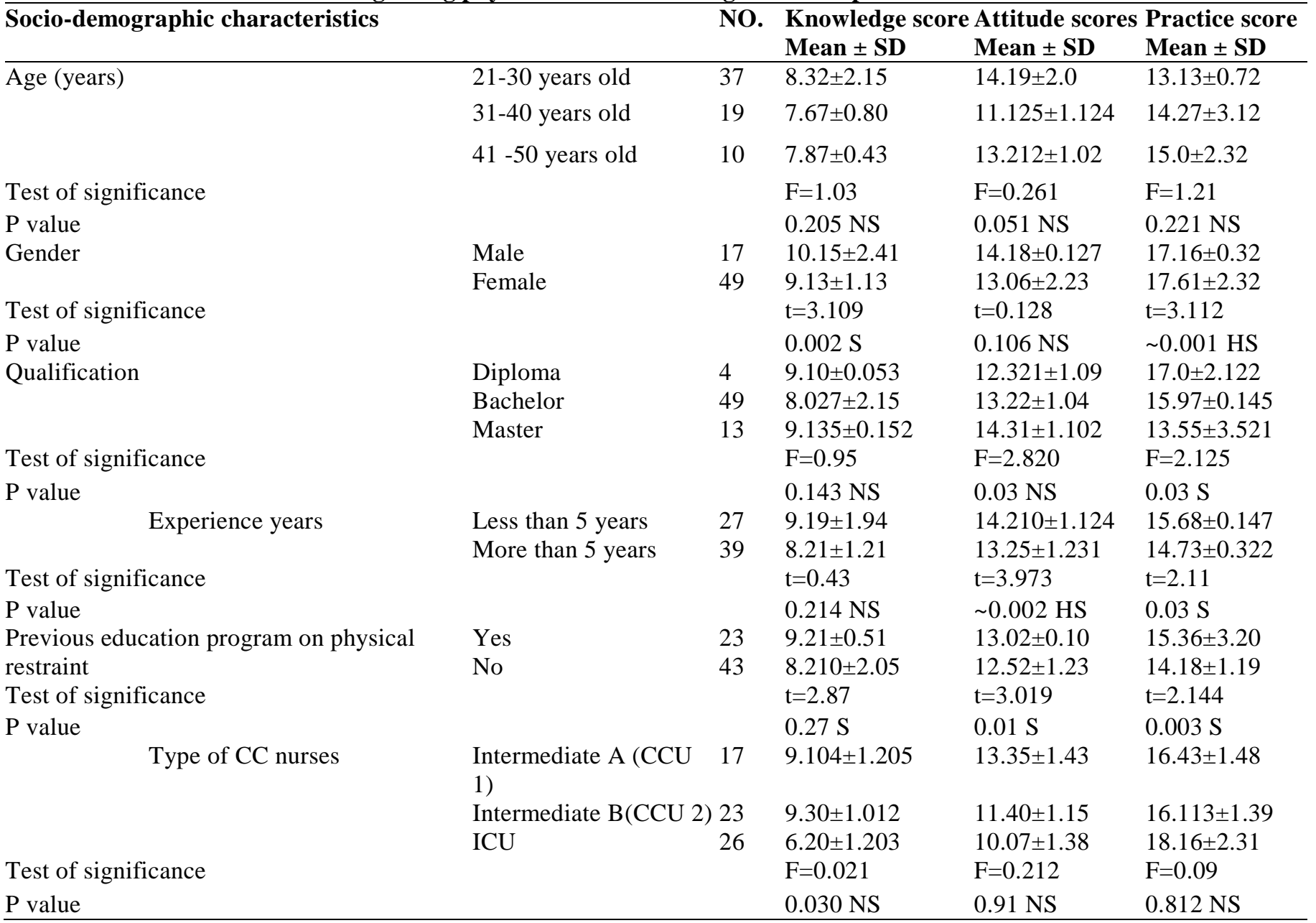

\section{Discussion}

[Citation: Ali, S., Gillani, S.A., Afzal, M., Perveen, K. (2020). Assessment of nurses management skills for critically ill patients. Biol. Clin. Sci. Res. J., 2020: 13 doi: https://doi.org/10.54112/bcsrj.v2020i1.13] 
Sick patients may have many problems, or other diagnoses may lead to changes in consciousness such as confusion and disturbance, causing a behavioral disorder. Therefore the use of physical restraints is helpful in the intervention of patients who resist during treatment. Physical restraint may create numerous adverse responses, so prevented patients need to prepare nurses with enough information and good training that gives them the right attitude and enables nurses to transform their care plan to avert issues of physical restraint (Rose et al., 2016). Evaluation of nurse's knowledge, attitudes, and practices regarding physical restraint are critical in collecting information about current and future nursing care to determine the quality of care provided to the patient and identify their weaknesses and strengths. The purpose of the current study was to evaluate nurse information, attitudes, and exercises regarding immune function among critically ill patients. Regarding the demographic features of the study sample the present study noted that, most of the evaluated nurses were women, their ages between 21 30 years old, and did not receive any previous education or training on physical restraint (Younis and Sayed Ahmed, 2017); which observed that the majority of the sample was female and aged between 20-30 years and did not attend any previous training or education program about physical restraint.As afar as the academic qualification is concerned the majority of nurses had graduate degrees with over 5 years of experience in nursing occupation inside ICU situations (Dolan and Dolan Looby, 2017); who stated that, Most of the nurses involved in their study practiced for many years in the ICU as a registered nurse in the attention of intensely sick patients; and they were nursing science graduates. The level of nurses` knowledge about application of physical restraints. The mean score of knowledge amongst nurse's was $8.352 \pm 2.92$ that reflected that they were fairly informed about the usage of physical restraints in seriously sick patients. This was not in agreement to the study results whom established that, the knowledge of nurses about using physical restraints was not appropriate (Gunawardena and Smithard, 2019; Kisacik et al., 2020). The application of physical restraints in critically ill patients was found through the attitude mean score in regards to use of physical restraints was $19.37 \pm 2.23$. This reflects that majority of nurses were having inadequate attitude associated with the practice of applying physical restraints to seriously sick patients (Al-Khaled et al., 2011; Luk et al., 2015; Unoki et al., 2020). Those studies claimed that the attitude of most nurses was negative in their exercise of applying physical restraints to the highly dependent patients. When the practice parameter of nurses with reference to physical restraints was studied, it was seen that the mean score was $17.08 \pm 2.09$. Approximately $91.7 \%$ of the nurses under study showed a good level of practice related to usage of physical restraints on severely sick subjects (Kisacik et al., 2020). They established that a fairly good number of their sample had adequate practice about application of physical restraints.

Evaluating the association of socio- demographic feature with \& nurses` knowledge, attitude $\&$ practice about physical restraints in severely ailing patients. The current study failed to establish any significant correlation between academic qualification and familiarity with physical restraints (Azab and Abu Negm, 2013; Chien and Lee, 2007; Suliman et al., 2017). They established that the knowledge of nurses having a graduate degree was not significantly different from diploma holder nurses. However the difference in practice parameter was statistically significant between academic degree and diploma holder nurses (McHugh and Lake, 2010; Oyesanya et al., 2016). They recognized that graduates (BSN) nurses were better than diploma holder nurses concerning expert practices. It was elaborated by these researchers that baccalaureate nurses accomplished extensive exercise on restraining during their enriched curricular scheme of studies during graduation. The present study succeeded to establish a positive relationship between gender and KAP of nurses (Kandeel and Attia, 2013; Taha and Ali, 2013). In their study no association was found between gender and KAP of nurses in physical restraints usage. We found a statistically significant association between the KAP score and the years of experience of nurses. These were similar to the findings by various researchers who agreed that with increase in experience time; the KAP score of nurses improves connected to physical restraints as compared to inexperienced or low experienced nurses (Hamers et al., 2009; Hofmann et al., 2015; Huang et al., 2009; Köpke et al., 2012).

\section{Conclusion}

In the current study it was concluded that level of nurses' knowledge was good, attitude was inadequate and practice was appropriate about physical restraints amongst serious patients. Furthermore, no significant relation was found between nurses' age and knowledge, attitude \& practice. However, correlation was positive between gender of the nurses but with practice and knowledge components only. Nurses' qualification had a positive correlation with practice parameter only. Lastly, the experience years of nurses were associated significantly only with practice and attitude scores. 


\section{Recommendation}

In light of findings of our study, the investigators suggest that professional instructive and academic curricula should be designed and workshops shall be arranged for nurses employed in entire critical care locations like ICUs to enrich them with sufficing training about physical restraint usage and their substitutes.The healthcare systems must adopt evidence-based procedures transcribed formally aimed at strategies or plans on physical restraint to be accessible to all nurses and doctors to ensure compliance.

\section{Conflict of interest}

The authors declared absence of any type of conflict of interest for manuscript publication.

\section{References}

Al-Khaled, T., Zahran, E., and El-Soussi, A. (2011). Nurses' related factors influencing the use of physical restraint in critical care units. $J$. Am. Sci 7, 13-22.

Ang, S. Y., Bakar Aloweni, F. A., Perera, K., Wee, S. L., Manickam, A., Lee, J. H. M., Haridas, D., Shamsudin, H. F., and Chan, J. K. (2015). Physical restraints among the elderly in the acute care setting: Prevalence, complications and its association with patients' characteristics. Proceedings of Singapore Healthcare 24, 137143.

Azab, S., and Abu Negm, L. (2013). Use of physical restraint in intensive care units (ICUs) at Ain Shams University hospitals, Cairo. Journal of American science 9, 230-240.

Chien, W.-T., and Lee, I. Y. (2007). Psychiatric nurses' knowledge and attitudes toward the use of physical restraint on older patients in psychiatric wards. International Journal of Multiple Research Approaches 1, 52-71.

De Jonghe, B., Constantin, J.-M., Chanques, G., Capdevila, X., Lefrant, J.-Y., Outin, H., and Mantz, J. (2013). Physical restraint in mechanically ventilated ICU patients: a survey of French practice. Intensive care medicine 39, 31-37.

Dolan, J., and Dolan Looby, S. E. (2017). Determinants of nurses' use of physical restraints in surgical intensive care unit patients. American Journal of Critical Care 26, 373-379.

Elsatar, A., and El-latief, O.-M. A. (2015). Nurses' Knowledge, Attitude and Practice towards Safety Physical Restraints use in intensive care unit. Zagazig Nursing Journal 11, 33-48.

Goethals, S., De Casterlé, B. D., and Gastmans, C. (2013). Nurses' ethical reasoning in cases of physical restraint in acute elderly care: a qualitative study. Medicine, Health Care and Philosophy 16, 983-991.

Gunawardena, R., and Smithard, D. G. (2019). The attitudes towards the use of restraint and restrictive intervention amongst healthcare staff on acute medical and frailty wards - a brief literature review. Geriatrics 4, 50.

Hamers, J. P., Meyer, G., Köpke, S., Lindenmann, R., Groven, R., and Huizing, A. R. (2009). Attitudes of Dutch, German and Swiss nursing staff towards physical restraint use in nursing home residents, a cross-sectional study. International journal of nursing studies 46, 248-255.

Hofmann, H., Schorro, E., Haastert, B., and Meyer, G. (2015). Use of physical restraints in nursing homes: a multicentre cross-sectional study. $B M C$ geriatrics 15, 129.

Huang, H.-T., Chuang, Y.-H., and Chiang, K.-F. (2009). Nurses' physical restraint knowledge, attitudes, and practices: the effectiveness of an in-service education program. Journal of Nursing Research 17, 241-248.

Kandeel, N. A., and Attia, A. K. (2013). Physical restraints practice in adult intensive care units in E gypt. Nursing \& health sciences 15, 79-85.

Kısacık, Ö. G., Sönmez, M., and Coşğun, T. (2020). Use of Physical Restraints in Critical Care Units: Nurses' Knowledge, Attitudes, and Practices. Critical Care Nurse 40, 37-47.

Köpke, S., Mühlhauser, I., Gerlach, A., Haut, A., Haastert, B., Möhler, R., and Meyer, G. (2012). Effect of a guideline-based multicomponent intervention on use of physical restraints in nursing homes: a randomized controlled trial. Jama 307, 2177-2184.

Luk, E., Burry, L., Rezaie, S., Mehta, S., and Rose, L. (2015). Critical care nurses' decisions regarding physical restraints in two Canadian ICUs: A prospective observational study. Canadian Journal of Critical Care Nursing 26.

Martin, B., and Mathisen, L. (2005). Use of physical restraints in adult critical care: a bicultural study. American Journal of Critical Care 14, 133-142.

McHugh, M. D., and Lake, E. T. (2010). Understanding clinical expertise: nurse education, experience, and the hospital context. Research in nursing \& health 33, 276-287.

Nasrate, H., Shamlawi, A., and Darawad, M. W. (2017). Improving ICU nurses' practices of physical restraints in Jordan: Effect of an educational program. Health 9, 1632-1643.

Oyesanya, T. O., Thomas, M. A., Brown, R. L., and Turkstra, L. S. (2016). Nurses' beliefs about caring for patients with traumatic brain injury. 
Western journal of nursing research 38, 11141138.

Phillips, K. (2013). Behavior Intervention-Seclusion $\&$ Restraints. Argumentative Essay, Restraints, EBSCO Publishing Inc.

Rose, L., Dale, C., Smith, O. M., Burry, L., Enright, G., Fergusson, D., Sinha, S., Wiesenfeld, L., Sinuff, T., and Mehta, S. (2016). A mixedmethods systematic review protocol to examine the use of physical restraint with critically ill adults and strategies for minimizing their use. Systematic reviews $\mathbf{5}, 1-8$.

Strout, T. D. (2010). Perspectives on the experience of being physically restrained: An integrative review of the qualitative literature. International Journal of Mental Health Nursing 19, 416-427.

Suliman, M., Aloush, S., and Al-Awamreh, K. (2017). Knowledge, attitude and practice of intensive care unit nurses about physical restraint. Nursing in critical care 22, 264-269.

Taha, N. M., and Ali, Z. H. (2013). Physical restraints in critical care units: impact of a training program on nurses' knowledge and practice and on patients' outcomes. J Nurs Care 2, 1-9.

Unoki, T., Hamamoto, M., Sakuramoto, H., Shirasaka, M., Moriyasu, M., Zeng, H., and Fujitani, S. (2020). Influence of mutual support and a culture of blame among staff in acute care units on the frequency of physical restraint use in patients undergoing mechanical ventilation. Acute medicine \& surgery 7, e479.

Younis, G. A., and Sayed Ahmed, S. (2017). Physical Restraint and Maintenance of critically ill patient's safety in Intensive Care Unit: Effect of Clinical practice guidelines on nurse's practice and attitude. Nurs Health Sci 6, 6-21. or exceeds the permitted use, you will need to obtain permission directly from the copyright holder. To view a copy of this licence, visit http://creativecommons.org/licen ses/by/4.0/.

(C) The Author(s) 2021

\section{(c) (†) \&}

Open Access This article is licensed under a Creative Commons Attribution 4.0 International License, which permits use, sharing, adaptation, distribution and reproduction in any medium or format, as long as you give appropriate credit to the original author(s) and the source, provide a link to the Creative Commons licence, and indicate if changes were made. The images or other third party material in this article are included in the article's Creative Commons licence, unless indicated otherwise in a credit line to the material. If material is not included in the article's Creative Commons licence and your intended use is not permitted by statutory regulation

[Citation: Ali, S., Gillani, S.A., Afzal, M., Perveen, K. (2020). Assessment of nurses management skills for critically ill patients. Biol. Clin. Sci. Res. J., 2020: 13 doi: https://doi.org/10.54112/bcsrj.v2020i1.13] 